\title{
Pengalaman Memoderasi Pengaruh Idealisme dan Komitmen pada Keputusan Etis Konsultan Pajak di Wilayah Provinsi Bali
}

\author{
Made Gede Wirakusuma ${ }^{1}$ \\ ${ }^{1}$ Fakultas Ekonomi dan Bisnis, Universitas Udayana, Indonesia \\ email:madegedewirakusuma@unud.ac.id
}

DOI: https://doi.org/10.24843/JIAB.2019.v14.i01.p02

\begin{abstract}
ABSTRAK
Jurnal Ilmiah Akuntansi dan Bisnis (JIAB)

https://ojs.unud.ac.id/index.php/jiab/ user/profile

Volume 14

Nomor 1

Januari 2019

Halaman 10-18

p-ISSN 2302-514X

e-ISSN 2303-1018

\section{INFORMASI ARTIKEL}

Tanggal masuk: 08 Oktober 2018

Tanggal revisi:

30 November 2018

Tanggal diterima:

12 Desember 2018

Konsultan pajak berperan penting sebagai mitra direktorat jenderal pajak meski sering mengalami dilema keputusan etis dalam menjalankan profesinya. Penelitian bertujuan untuk mengungkapkan faktor pengalaman yang bersifat kontinjen memengaruhi hubungan idealisme dan komitmen profesional pada keputusan etis konsultan pajak. Survei menggunakan kuesioner dikirimkan kepada responden yaitu anggota IKPI (Ikatan Konsultan Pajak Indonesia) Wilayah Bali. Penyampelan menggunakan teknik purposive. Sejumlah 90 kuesioner dari 109 (useable response rate 84,1\%), selanjutnya data dianalisis dengan regresi moderasian. Hasil pengujian menunjukkan pengalaman memperkuat pengaruh positif hubungan antara idealisme dan keputusan etis konsultan pajak, sementara pengalaman tidak berpengaruh pada hubungan antara komitmen professional dan keputusan etis konsultan pajak di wilayah Bali.

Kata kunci: Keputusan etis, idealisme, komitmen profesional, pengalaman

\section{Role of Experience as a Moderator of the Effect of Idealism and Commitment on Ethical Decision-Making by Tax Consultants in the Province of Bali}

ABSTRACT

Tax consultants are indispensable as associates of the Direktorat Jendral Pajak to help in raising awareness about the importance of taxpayer compliance. This study aims to determine the influence of experience on the relationship between idealism and professional commitment to ethical decision-making by tax consultants. The questionnaires were sent to the respondents/sample (members of Ikatan Konsultan Pajak Indonesia [IKPI]) of Bali Province. The sample was determined using the purposive sampling technique. Ninety questionnaires from 109 respondents working as tax consultants in Bali Province were collected as a pilot research, with a useable response rate of $84.1 \%$. The results of the moderated regression analysis (MRA) analysis demonstrate that experience reinforces the positive influence of the relationship between idealism and ethical decisions of tax consultants, while it has no effect on the relationship between professional commitment and ethical decision-making by tax consultants in Bali Province.
\end{abstract}

\section{PENDAHULUAN}

Pemerintah Indonesia berupaya untuk meningkatkan realisasi penerimaan pajak, seperti misalnya dengan menerapkan penghitungan pajak secara mandiri (self assessment system) bagi wajib
Keywords: Ethical decision, idealism, professional commitment, experience 
dan Tarjo dan Kusumawati (2006) menemukan bahwa pelaksanaan self assessment system belum berjalan dengan baik. Seringkali kasus pelaporan pajak muncul akibat kurangnya pemahaman wajib pajak atas aturan perpajakan sehingga peran konsultan pajak sangat diperlukan oleh wajib pajak, terlebih lagi ketika ada kebijakan baru terkait perpajakan oleh pemerintah Indonesia, seperti Tax Amnesty Juli 2016 lalu. Kecenderungan wajib pajak membutuhkan konsultan pajak dengan tujuan untuk akurasi pelaporan, untuk meminimalkan pajak, adanya ketakutan terhadap sanksi, termasuk juga karena alasan ketidakcukupan waktu (Devos, 2012).Dengan demikian, profesi konsultan pajak menjadi sangat penting namun dilematis karena berbagai kebutuhan wajib pajak berpotensi bertentangan dengan peraturan sehingga dapat mempengaruhi kredibilitas dan integritas diri.

Achmad (2014) menyatakan bahwa Profesi ideal konsultan pajak harus memiliki independensi, profesionalisme, dan integritas dalam menjalankan bisnis jasanya. Blanthorne et al. (2014) menyatakan bahwa adanya masalah dual agency pada hubungan antara konsultan pajak dengan klien; di satu sisi konsultan pajak perlu membina hubungan baik dengan klien, namun disisi lain konsultan pajak memiliki kewajiban untuk mematuhi peraturan pajak. Dilema etis bagi konsultan pajak adalah harus membuat suatu keputusan yang bertentangan dengan prinsip-prinsip profesinyasementara imbalan ekonomis cukup material dan mempengaruhi kelanjutan jasa yang diberikan.

Peraturan Menteri Keuangan Nomor 111/ PMK.03/2014 Pasal 28 dan 29 mengatur pengawasan yang sangat ketat bagi para konsultan pajak.Telah terbukti beberapa konsultan pajak yang ada di kota-kota besar harus dibekukan dan bahkan dicabut ijinnya karena klien yang ditangani terbukti melanggar ketentuan perpajakan dan berkasus pidana.Selain pelanggaran kode etik yang menjurus pada pelanggaran pidana, terdapat pelanggaran etik lain juga seperti perebutan klien meskipun sudah diatur secara jelas dalam AD/ART IKPI tentang Kode Etik Konsultan Pajak.

Dilema etika bagi suatu profesi dapat diatasi dengan beberapa faktor, seperti orientasi etika yang dibentuk oleh idealisme diri (Forsyth, 1980; Higgins dan Kelleher, 2005) agar mampu menjaga independensi dan integritas diri dalam membuat suatu keputusan. Sementara Larkin (1990) menyatakan dilemma etika dapat diatasi dengan komitmen profesional yang mengandung loyalitas pada profesi yang dimiliki oleh individu.Di sisi lain, pengalaman juga memberikan dampak pada setiap keputusan yang diambil oleh konsultan pajak (Budi,dkk. 2004; Oktavia, 2006). Konsultan pajak yang berpengalaman cenderung akan lebih berani dan lebih cepat dalam mengambil keputusan, mengingat pengalaman yang dimiliki dalam hal perpajakan. Namun sebaliknya, konsultan pajak dengan pengalaman yang tidak terlalu lama akan lebih berhati-hati dalam pengambilan keputusan karena kurangnya pengalaman tersebut.

Beberapa penelitian terkait keputusan etis telah dilakukan sebelumnya, seperti penelitian Shaub et al. (1993); Fallah (2006); Gusti dan Syahril (2007); Aziza dan Salim (2007); Januarti (2011); Abdurrahman dan Yuliani (2011); Uyar dan Ozer (2011); dan Ashari (2013). Terdapat inkonsistensi hasil penelitian yang menunjukkan bahwa keputusan etis seorang professional (konsultan pajak) sehingga menjadi sebuah fenomena yang menarik untuk diungkapkan lebih lanjut. Penelitian ini menguji adanya peran pengalaman yang dapat memperkuat pengaruh idealisme dan komitmen professional pada keputusan etis yang dibuat oleh konsultan pajak di wilayah Bali.

Keputusan etis pada hakekatnya dilandaskan kepada Teori Etika yang menunjukkan penilaian normatif tentang perilaku seseorang sudah benar atau sudah sesuai dengan yang seharusnya dilakukan (Brooks, 2007). Kebutuhan akan etika muncul dari keinginan untuk menghindari permasalahanpermasalahan di dunia nyata. Etika merupakan tatanan moral yang telah disepakati bersama dalam suatu profesi dan ditujukan untuk anggota profesi. Etika menjadi salah satu panduan bagi profesi (akuntansi) dalam mempertanggungjawabkan segala aktivitasnya (Januarti, 2011), termasuk dalam aktivitas pembuatan suatu keputusan, dengan harapan keputusan-keputusan yang dibuat tersebut merupakan keputusan yang etis.

Sementara dari sudut Teori perkembangan moral kognitif (Cognitive Moral Development) oleh Kohlberg (1969) dengan tahapan perkembangan moral seseorang disajikan pada Tabel 1.

Keputusan etis (ethical decision) merupakan keputusan yang baik secara legal maupun moral yang dapat diterima oleh masyarakat luas (Trevino, 1986). Rest et al. (2002) menyatakan empat tahapan dalam model pembuatan keputusan etis, yaitu (1) pemahaman tentang adanya isu moral dalam sebuah dilemma etika (2) pengambilan keputusan etis, (3) Moral Intention(4) Moral Behavior. 
Tabel 1: Tahapan Cognitive Moral Development Kohlberg

Level
Hal Yang Benar
Level 1: Pre-Conventional

Tingkat 1: Orientasi Ketaatan dan hukuman (Punishment and Obedience Orientation)

Tingkat 2: Pandangan Individualistik (Instrumental Relativist Orientation)

Level 2: Conventional

Tingkat 3: Mutual Ekspektasi interpersonal, hubungan dan kesesuaian ("good boy or nice girl" orientation)

Tingkat 4: Sistem social dan hati nurani (Law and order orientation)

Level 3: Post-Conventional

Tingkat 5: Kontrak social dan hak individual (social-contract legal Orientation)

Tingkat 6: Prinsip etika universal (universal ethical principle orientation)
Menghindari pelanggaran aturan untuk menghindari hukuman atau kerugian. Kekuatan otoritas superior menentukan "right". Mengikuti aturan ketika sesuai dengan kepentingan pribadi dan membiarkan pihak lain melakukan hal yang sama. "right" didefinisikan dengan equal exchange, suatu kesepakatan yang fair.

Memperlihatkan stereotype peilaku yang baik. Berbuat sesuai dengan apa uyang diharapkan pihak lain.

Mengikuti aturan hukum dan masyarakat (social, legal, dan system keagamaan) dalam usaha untuk memelihara kesejahteraan masyarakat.

Mempertimbangkan kebaikan masyarakat, akan tetapi masih menekankan aturan dan hukum.

Bertindak sesuai dengan pemilihan pribadi prinsip etika keadilan dan hak (perspektif rasionalitas individu yang mengakui sifat moral)

Sumber : Kohlberg, 1969

Sementara Jones (1991) menyatakan ada 3 unsur utama dalam pembuatan keputusan etis, meliputi moral issue, moral agent, dan keputusan etis (ethical decision) itu sendiri.Adapun faktorfaktor individu mempengaruhi pembuatan keputusan etis yaitu idealisme (Shaub et al. 1993; Januarti, 2011; Abdurrahman dan Yuliani, 2011; Uyar dan Ozer,2011), komitmen profesional (Abdurrahman dan Yuliani,2011) dan skeptisme profesional (Gusti dan Syahril, 2008).

Idealisme menurut Forsyth (1980) dan Shaub et al. (1993) mengidentifikasi bahwa idealisme dan relativisme sebagai prediktor penting penilaian moral.Sikap idealis diartikan sebagai sikap tidak memihak dan terhindar dari berbagai kepentingan.Forsyth (1980) berpendapat bahwa orientasi etika adalah tujuan utama perilaku profesional yang berkaitan erat dengan moral dan nilai-nilai yang berlaku dan digerakkan oleh dua karakteristik yaitu idealisme dan relativisme.Sikap idealis jugadiartikan sebagai sikap tidak memihak dan terhindar dari berbagai kepentingan. Seorang akuntan yang tidak bersikap idealis, hanya akan mementingkan dirinya sendiri agar mendapat fee yang tinggi dengan meninggalkan sikap independensi. Sama halnya dengan seorang akuntan, seorang konsultan pajak juga perlu mempertahankan idealismenya dalam menjalankan kewajibannya sebagai perpanjangan tangan dari pemerintah dalam rangka meningkatkan kepatuhan wajib pajak.

$\mathrm{H}_{1}$ : Pengalaman memperkuat pengaruh idealisme pada keputusan etis konsultan pajak yang terdaftar di Wilayah Provinsi Bali

Komitmen menurut Robbins dan Judge (2007) sebagai keterlibatan pekerjaaan yang tinggi berarti memihak pada pekerjaan tertentu seseorang individu. Komitmen organisasional yang tinggi berarti memihak organisasi yang merekrut individu tersebut. Individu yang memiliki komitmen tinggi kemungkinan akan melihat dirinya sebagai anggota sejati organisasi. Kwon dan Banks (2004) menyatakan bahwa komitmen profesional diperkirakan oleh dukungan untuk kelompok, sikap positif terhadap profesi dan karakteristik pekerjaan. Komitmen profesional merupakan sikap positif terhadap suatu profesi untuk tetap menjaga nama baik profesi. Dalam penelitian ini, lebih ditekankan pada komitmen profesional karena objek penelitian ini adalah konsultan pajak terdaftar yang bernaung dalam suatu asosiasi yang disebut IKPI (Ikatan Konsultan Pajak Indonesia). 
Asosiasi IKPI ini memiliki kode etik tersendiri dalam mengontrol setiap tindakan dari anggotanya.

Pengalaman adalah proses pembelajaran dan pertambahan potensi tingkah laku yang diperoleh dari pendidikan formal maupun non formal (Knoers dan Haditono, 1999). Pengalaman bagi konsultan pajak dapat diperoleh melalui pelatihan, supervisi, maupun review kinerja yang pernah dilakukan dalam hal perpajakan.Januarti (2011) berpendapat bahwa pengalaman seorang auditor selalu berkembang searah dengan pengalaman audit, diskusi audit, pelatihan, dan penggunaan standar. Auditor yang memiliki pengalaman dianggap lebih konservatif saat mengahadapi dilema etika (Larkin, 2000).Sikap konservatif tersebut membantu auditor untuk meningkatkan sensitivitas etikanya. Gusnardi (2003) mengukur pengalaman audit melalui jabatan auditor, lama bekerja, peningkatan keahlian, serta pelatihan audit yang pernah diikuti. Pengalaman didasarkan pada asumsi bahwa tugas yang dilakukan secara berulang-ulang memberikan peluang untuk belajar melakukannya dengan yang terbaik.

Untuk pengembangan hipotesis penelitian ini, mengacu dari pernyataan Shaub et al. (1993) bahwa orientasi etis mempengaruhi sensitivitas etika. Hasil penelitian Januarti (2011) menemukan bahwa orientasi etika berpengaruh signifikan terhadap persepsi dan pertimbangan etis.Abdurrahman dan Yuliani (2011) serta Uyar dan Ozer (2011) menemukan bahwa orientasi etika yang diukur dengan skala idealisme berpengaruh signifikan terhadap pembuatan keputusan etis. Hal ini bermakna bahwa semakin meningkat idealisme konsultan pajak, maka keputusan yang dibuat oleh konsultan pajak tersebut akan semakin etis.

Komitmen profesional merupakan loyalitas pada profesi yang dimiliki oleh individu (Larkin,1990). Penelitian Abdurrahman dan Yuliani (2011) menemukan bahwa komitmen profesional berpengaruh signifikan terhadap pembuatan keputusan etis. Jeffrey dan Weatherholt (1996), komitmen profesional yang kuat akan mengarahkan professional untuk taat pada aturan.

Pengalaman merupakan tugas yang dilakukan secara berulang-ulang memberikan peluang untuk belajar melakukan dengan cara terbaik dan dapat digunakan untuk meningkatkan kinerja pengambilan keputusan (Knoers dan Haditono, 1999). Jones (1991) juga menyatakan bahwa perkembangan moral kognitif seseorang dipengaruhi oleh pengalaman. Hal ini menunjukkan bahwa pengalaman seorang konsultan pajak akan berkaitan dengan keputusan etis yang diambilnya. Berdasarkan penjelasan di atas maka dapat dirumuskan 2 hipotesis dalam bentuk alternatif sebagai berikut.

$\mathrm{H}_{2}$ : Pengalaman memperkuat pengaruh komitmen pada keputusan etis konsultan pajak yang terdaftar di Wilayah Provinsi Bali

\section{METODE PENELITIAN}

Penelitian ini dilaksanakan kepada para konsultan pajak bersertifikasi di wilayah Provinsi Bali sebagai responden penelitian. Bali sebagai wilayah yang memiliki tingkat pertumbuhan yang tinggi dengan tingkat heterogenitas pengusaha atau usaha, sudah tentu membutuhkan jasa para konsultan pajak guna memenuhi kewajiban kepada Negara.

Jenis data berdasarkan sifatnya dalam penelitian ini adalah data kualitatif yang dikuantifikasi. Berdasarkan sumbernya, penelitian ini menggunakan data primer berupa data yang dikumpulkan melalui penyebaran kuesioner.

Populasi penelitian ini adalah para konsultan pajak yang ada di seluruh wilayah provinsi Bali.Sampel penelitian ditentukan dengan metode purposive random sampling yaitu konsultan pajak di wilayah Bali yang bersertifikasi.

Variabel dependen dalam penelitian ini adalah keputusan etis, sementara variabel independen adalah idealism dan komitmen professional, sedangkan variabel pemoderasi adalah pengalaman dari para konsultan pajak.

Pengukuran variabel menggunakan skala Likert empat poin untuk mengukur sikap, pendapat, dan persepsi responden tentang fenomena sosial, dan jika skala ini digunakan dalam pengukuran akan menghasilkan data interval atau rasio (Sugiyono,2009).

Pengukuran variabel Keputusan Etis menggambarkan kemampuan konsultan pajak dalam membuat suatu keputusan yang telah memenuhi peraturan dan nilai-nilai etika yang berlaku. Variabel pembuatan keputusan etis (Y) diukur dengan menggunakan empat skenario kasus yang merupakan modifikasi dari pengukuran pembuatan keputusan etis dalam penelitian Abdurrahman dan Yuliani (2011), dengan indikator Fleksibilitas, Kepatuhan terhadap peraturan, Pemenuhan kepentingan klien, dan Sabotase klien rekan seprofesi. Instrumen yang digunakan untuk mengukur keputusan etis terdiri dari 4 kasus berbeda dengan skala likert 4 poin yaitu sangat tidak setuju (STS), 
tidak setuju (TS), setuju (S), dan sangat setuju (SS). Responden diminta memberikan tanggapan terhadap masing-masing kasus tersebut.Pada kasus yang positif dengan nilai skor yang tinggi menunjukkan seorang konsultan pajak mengambil keputusan dengan lebih etis.Demikian sebaliknya.Kemudian skor pada setiap kasus, akan dijumlahkan dalam total skor variabel keputusan etis.

Idealisme merupakan sikap tidak memihak dan terhindar dari berbagai kepentingan. Penelitian yang dilakukan oleh Januarti (2011) membuat pernyataan untuk pengukuran idealisme dengan mengacu pada suatu hal yang dipercaya oleh individu yang tidak melanggar nilai-nilai moral, dengan indikator Evaluasi tindakan, Toleransi, Tindakan fisik dan psikologis, dan Penilaian moral. Instrumen yang digunakan untuk mengukur idealism terdiri dari 6 pernyataan berbeda dengan skala likert 4 poin yaitu sangat tidak setuju (STS), tidak setuju (TS), setuju (S), dan sangat setuju (SS). Responden diminta memberikan tanggapan terhadap setiap pernyataan dan pada pernyataan positif nilai skor yang tinggi menunjukkan seorang konsultan pajak memiliki idealisme yang tinggi. Demikian sebaliknya.Kemudian skor pada masingmasing pernyataan nantinya akan dijumlahkan untuk mengetahui total skor pada variabel idealisme.

Komitmen Profesional merupakan tingkat loyalitas seorang individu pada profesi, seperti yang dipersepsikan oleh individu tersebut (Larkin,1990). Komitmen profesional menunjukkan sikap individu dari konsultan pajak yang loyal terhadap profesinya serta menolak perilaku-perilaku yang akan mendeskreditkan profesinya. Komitmen profesional diukur dengan menggunakan enam item pernyataan yang dikembangkan dari penelitian Januarti (2011), dengan indikator Kesadaran dan sukarela, Kebanggaan pada profesi, Motivasi, Pengorbanan, Pengembangan diri, dan Kepedulian pada profesi. Instrumen yang digunakan untuk mengukur komitmen professional terdiri dari 8 pernyataan berbeda dengan skala likert 4 poin yaitu sangat tidak setuju (STS), tidak setuju (TS), setuju (S), dan sangat setuju (SS). Responden diminta memberikan tanggapan terhadap masingmasing pernyataan tersebut. Pada pernyataan positif dengan nilai skor skala likert yang tinggi menunjukkan seorang konsultan pajak memiliki komitmen professional yang tinggi, dan demikian pula sebaliknya. Kemudian skor pada masing-masing pernyataan nantinya akan dijumlahkan untuk mengetahui total skor pada variabel komitmen profesional.
Pengalaman adalah proses pembelajaran dan pertambahan potensi tingkah laku yang diperoleh dari pendidikan formal maupun non formal (Knoers dan Haditono, 1999). Variabel pengalaman diukur dengan menggunakan 4 indikator yang dikembangkan Gusnardi (2003) meliputi, jabatan, lama bekerja, peningkatan keahlian, pelatihan yang pernah diikuti, serta jumlah klien (wajib pajak) yang pernah ditangani.

Teknik analisis yang digunakan adalah Moderated Regression Analysis (MRA). Sebelum dilakukan pengujian, terlebih dahulu dilakukan uji asumsi klasik yaitu Uji Normalitas, dan Heteroskedastisitas. Formula yang digunakan adalah sebagai berikut ini.

$$
K E=\alpha+\beta_{1} I+\beta_{2} K+\beta_{3} P+\beta_{4} I^{*} P+\beta_{5} K^{*} P+\varepsilon
$$

Keterangan:

$$
\begin{array}{ll}
\mathrm{KE} & =\text { Keputusan Etis } \\
\mathrm{I} & =\text { Idealisme } \\
\mathrm{K} & =\text { Komitmen } \\
\mathrm{P} & =\text { Pengalaman } \\
\mathrm{I}^{*} \mathrm{P} & =\text { Interaksi Idealisme dan Pengalaman } \\
\mathrm{I}^{*} \mathrm{~K} & =\text { Interaksi Komitmen dan Pengalaman } \\
\beta_{1}-\beta_{5} & =\text { Koefisien Regresi } \\
\alpha & =\text { Konstanta } \\
\varepsilon & =\text { Error term }
\end{array}
$$

\section{HASIL DAN PEMBAHASAN}

Gambaran umum responden berdasarkan Direktori IKPI Pengda Bali-Nusa Tenggara tahun 2016, terdapat 114 (seratus empat belas) orang konsultan pajak terdaftar di Wilayah Bali-Nusa Tenggara.Terdapat 5 konsultan beralamatkan di luar wilayah Bali sehingga kuesioner disebarkan kepada 109 konsultan pajak yang terdaftar pada Direktori IKPI dan beralamat di Wilayah Bali.Kuesioner kembali sejumlah 107 namun yang dapat digunakan hanya 90 kuesioner karena responden tidak melengkapi persyaratan.

Uji Validitas menunjukkan tidak ada masalah dengan validitas setiap pernyataan yang dikandung instrumen untuk mengukur semua variabel dalam penelitian ini.Untuk uji reliabilitas instrumen menunjukkan nilai Cronbach Alpha di atas 0,70 sehingga dapat disimpulkan bahwa semua variabel dalam penelitian ini adalah andal/reliabel.

Hasil uji normalitas menunjukkan nilai Kolmogorov-Smirnov adalah 0,448 dan koefisien Asymp.sig (2-tailed) $=0,988$, lebih besar dari $\alpha=0,05$ artinya, semua variabel dalam penelitian ini berdistribusi normal. 
Uji heteroskedastisitas dianalisis melalui uji Glejserdan menunjukkan variable idealisme, komitmen profesional dan skeptisme profesional tidak berpengaruh signifikan terhadap pembuatan keputusan etis, karena signifikansi setiap variabel bebas lebih dari taraf nyata (a) yaitu 5\%.Jadi dapat disimpulkan bahwa tidak terjadi heteroskedastisitas.

Statistik deskriptif dalam penelitian ini disajikan untuk memberikan informasi tentang karakteristik setiap variabel penelitian dalam tabel berikut.

Tabel 2: Statistik Deskriptif

\begin{tabular}{lrrr}
\hline & Mean & Std. Deviation & \multicolumn{1}{c}{$\mathrm{N}$} \\
\hline Keputusan etis & 13,07 & 1,747 & 90 \\
Idealisme & 20,58 & 1,872 & 90 \\
Komitmen professional & 27,74 & 3,049 & 90 \\
Pengalaman & 12,32 & 2,103 & 90 \\
Idealisme*pengalaman & 255,60 & 58,937 & 90 \\
Komitmen prof*pengalaman & 345,43 & 85,612 & 90 \\
\hline
\end{tabular}

Sumber: Data primer diolah, 2017

Berdasarkan nilai rata-rata dan deviasi standar masing-masing variabel penelitian maka dapat dinyatakan bahwa semua nilai deviasi standar lebih rendah dari nilai rata-rata. Hal ini mencerminkan rata-rata respon responden pada setiap variabel bernilai cukup tinggi dan simpangan respon tidak menunjukkan tingginya bias distribusi data yang diujikan.

Analisis model fit (kelayakan model) menunjukkan nilai Adjusted $\mathrm{R}$ square $\left(\mathrm{R}^{2}\right)$ yang memadai sebesar 0,441 yang berarti bahwa variasi variabel keputusan etis dijelaskan sebesar $44,1 \%$ oleh variasi variabel idealism, komitmen professional, pengalaman dan interaksi idealism-pengalaman serta interaksi komitmen-pengalaman. Nilai $\mathrm{F}$ sebesar 15,069 dengan nilai signifikansi 0,000 yang lebih kecil dari 5\% mengindikasikan bahwa variabel idealisme, komitmen professional, pengalaman dan interaksi idealism-pengalaman serta interaksi komitmenpengalaman berpengaruh secara serempak pada pembuatan keputusan etis pada tingkat signifikansi 5\%, atau dapat dikatakan modelfit.

Ringkasan hasil pengujian statistik disajikan pada Tabel 3. Hasil pengujian Hipotesis 1 menunjukkan koefisien regresi interaksi idealisme*pengalaman bernilai positif dengan signifikansi 0.042 (lebih kecil dari 5\%) mengindikasikan adanya pengaruh pengalaman konsultan pajak pada hubungan idealisme dan keputusan etis. Semakin tinggi idealisme seorang konsultan pajak maka akan semakin tinggi mempengaruhi keputusan etis yang dibuatnya seiring dengan semakin berpengalamannya konsultan pajak tersebut. Seorang konsultan pajak akan mempertimbangkan kebaikan bagi masyarakat serta ketaatan hukum, dimana konsultan pajak dalam membuat keputusan senantiasa berusaha agar tidak melanggar hak-hak dari pihak lain, baik yang berinteraksi secara langsung maupun yang tidak berinteraksi secara langsung dengan konsultan pajak. Sesuai dengan Cognitive Moral Development Theory pada Post-Conventional level, bahwa orang mulai mempertimbangkan hal-hal yang baik bagi masyarakat akan tetapi tetap taat pada aturan hukum yang berlaku dalam membuat suatu keputusan yang etis. Hasil penelitian ini konsisten dengan penelitian Aziza dan Salim (2007), Januarti (2011), Uyar dan Ozer (2011) yang menyatakan bahwa idealisme yang tinggi cenderung untuk tidak membuat keputusan yang bertentangan dengan nilai-nilai moral dibandingkan dengan akuntan yang memiliki sikap relativis. Hasil penelitian ini juga searah dengan penelitianNadirsyah (2007) yang menyatakan bahwa pengalaman auditor berpengaruh positif terhadap keputusan etis auditor.Gusnardi (2003) mengukur pengalaman melalui jabatan, lama bekerja, peningkatan keahlian, serta pelatihan yang pernah diikuti. Penggunaan pengalaman didasarkan pada asumsi bahwa tugas yang dilakukan secara berulangulang memberikan peluang untuk belajar melakukannya dengan yang terbaik.Hasil penelitian ini menunjukkan bahwa konsultan pajak yang semakin berpengalaman, akan cenderung membuat keputusan yang semakin etis seiring dengan tingkat idealism diri yang dimiliki. Dengan demikian, pengembangan pengalaman sebaiknya semakin ditingkatkan dan senantiasa menjaga idealism dalam membuat keputusan-keputusan yang tepat ketika menghadapi dilema etika.

Hipotesis kedua $\left(\mathrm{H}_{2}\right)$ menyatakan bahwa pengalaman memoderasi pengaruh komitmen profesional pada pembuatan keputusan etis konsultan pajak di wilayah Bali. Hasil pengujian menunjukkan pengalaman tidak memperkuat pengaruh komitmen profesional pada pembuatan keputusan etis. Dengan 
Tabel 3: Uji Statistik t Pada Analisis Regresi Moderasian-MRA

\begin{tabular}{|c|c|c|c|c|c|}
\hline \multirow[b]{2}{*}{ Model } & \multicolumn{2}{|c|}{$\begin{array}{l}\text { Unstandardized } \\
\text { Coefficients }\end{array}$} & \multirow{2}{*}{$\begin{array}{c}\begin{array}{c}\text { Standardized } \\
\text { Coefficients }\end{array} \\
\text { Beta } \\
\end{array}$} & \multirow[b]{2}{*}{$\mathrm{t}$} & \multirow[b]{2}{*}{ Sig. } \\
\hline & $\mathrm{B}$ & Std. Error & & & \\
\hline (Constant) & 16,073 & 8,034 & & 2,001 & 049 \\
\hline Idealisme & ,588 & ,438 & ,630 & 1,343 & 183 \\
\hline Komitmen professional & ,216 & 351 & 377 & 615 &, 540 \\
\hline Pengalaman & 974 & 674 & 1,173 & 1,445 &, 152 \\
\hline Idealisme * pengalaman &, 065 & 034 & 2,195 & 1,888 &, 042 \\
\hline $\begin{array}{l}\text { Komitmen professional * pengalaman } \\
\text { Adjusted } \mathrm{R}^{2} 0,441\end{array}$ & ,004 & ,029 & ,216 & , 150 & ,881 \\
\hline 15,069 & & & & & \\
\hline P-Value & & & & & \\
\hline
\end{tabular}

a. Dependent Variable: keputusan etis

Sumber: Data primer diolah, 2017

kata lain, tingginya komitmen dari konsultan pajak terhadap profesinya, tidak mempengaruhi keputusan yang dibuatnya akan semakin etis tanpa memperhatikan tingkat pengalaman yang dimiliki. Hasil penelitian ini sejalan dengan penelitian Aziza dan Salim (2007) yang menyatakan bahwa komitmen profesional tidak berpengaruh terhadap kepekaan auditor terhadap masalah-masalah etis.Demikian pula dengan penelitian Januarti (2011) yang menyatakan komitmen profesional tidak berpengaruh terhadap persepsi dan pertimbangan etis. Hal ini kemungkinan disebabkan karena kurangnya peranan organisasi profesi dalam memberikan responden kesempatan untuk mengembangkan diri melalui pelatihan-pelatihan maupun forum diskusi, sehingga responden tidak menganggap komitmen profesional sebagai sesuatu yang penting. Secara umum, hasil penelitian ini menunjukkan bahwa tinggi-rendahnya komitmen profesional seorang konsultan pajak, akan cenderung tidak mempengaruhi pembuatan keputusan etis meskipun memiliki pengalaman yang cukup tinggi. Namun demikian, terdapat hubungan positif yang mencerminkan bahwa sesungguhnya semakin tinggi komitmen professional seorang konsultan pajak maka akan semakin tinggi pertimbangan etis dalam pembuatan keputusannya, seiring pula dengan tingginya tingkat pengalaman yang dimiliki.

Sesuai dengan tujuan penelitian untuk menguji pengaruh pengalaman yang memperkuat hubungan antara idealisme, dan komitmen profesional pada keputusan etis konsultan pajak berimplikasi kepada upaya Ikatan Konsultan Pajak Indonesia Wilayah Bali untuk menjaga Idealisme setiap anggota dan juga sekaligus meningkatkan komitmen terhadap asosiasi profesi melalui kegiatan-kegiatan pelatihan dan sosialisasi secara bersama-sama. Asosiasi profesi konsultan pajak diharapkan juga untuk menetapkan kualifikasi pengalaman bagi seorang konsultan pajak sehingga keputusan etis yang dibuat dapat lebih ditingkatkan, kredibel dan berintegritas, terutama untuk menjaga kepercayaan dan kesinambungan profesi konsultan pajak, terlebih mengemban tugas perpanjangan pemerintah dalam meningkatkan pendapatan negara dari sektor pajak.

\section{SIMPULAN}

Berdasarkan hasil pengujian dan pembahasan, maka dapat disimpulkan bahwa (1) Pengalaman konsultan pajak memperkuat secara positif hubungan antara idealisme dan pembuatan keputusan etis. Semakin tinggi idealisme seorang konsultan pajak maka akan semakin tinggi mempengaruhi keputusan etis yang dibuatnya seiring dengan semakin berpengalamannya konsultan pajak tersebut. Peningkatan pengalaman bagi seorang konsultan pajak akansemakin dibutuhkan dan senantiasa menjaga idealisme dalam membuat keputusankeputusan yang tepat ketika menghadapi dilema etika. (2)Pengalaman tidak memperkuat pengaruh komitmen profesional pada pembuatan keputusan etis. Tingginya komitmen dari konsultan pajak terhadap profesinya, tidak mempengaruhi keputusan yang dibuatnya akan semakin etis sekalipun tingkat pengalaman yang dimiliki cukup tinggi. Namun demikian, terdapat hubungan positif yang mencerminkan bahwa sesungguhnya semakin tinggi komitmen professional seorang konsultan pajak maka akan semakin tinggi pertimbangan etis dalam pembuatan keputusannya, seiring pula dengan tingginya tingkat pengalaman yang dimiliki. 
Berdasarkan respon dari responden terkait idealisme, maka perlu ditingkatkan pemahaman seorang konsultan pajak dalam menerapkan peraturan perpajakan yang berlakusehingga diharapkan mampu menjaga idealism dalam menjalankan profesinya. Demikian pula terkait pengalaman, konsultan pajak diharapkan untuk meningkatkan jumlah wajib pajak dan tingkat kompleksitas wajib pajak yang ditangani.

Penelitian selanjutnya diharapkan untuk mengembangkan penelitian terkait faktor-faktor yang mempengaruhi pembuatan keputusan etis konsultan pajak dengan memperhatikan kondisi eksternal atau lingkungan.

\section{REFERENSI}

Abdurrahman, dan Yuliani, Nur L. 2011. Determinasi Pengambilan Keputusan Etis Auditor Internal (Studi Empiris Pada BUMN dan BUMD di Magelang dan Tumanggung). Widya Warta Volume 2, hal. 133-150.

Achmad, T. 2014. Menjadikan Konsultan Pajak sebagai Agents of Tax Compliance. Website: http://www. pajak.go.id/ content/article/ menjadikan-konsultan-pajak-sebagai-agentstaxcompliance.

Ashari, 2013.Corruption Awareness, Ethical Sensitivity, Professional Skepticism And Risk Of Corruption Assessment: Exploring The Multiple Relationship In Indonesian Case. Availablefrom: www.ssrn.com.

Aziza, N. dan Salim A. 2007.Pengaruh Orientasi Etika Pada Komitmen dan Sensitivitas Etika Auditor (Studi Empiris pada Auditor di Bengkulu dan Sumatera Selatan). Simposium Nasional Akuntansi XI. Pontianak 23 - 24 Juli 2008.

Blanthorne, C., H. A. Burton dan Fisher, D. 2014.The Aggressiveness of Tax Professional Reporting: Examining the Influence of Moral Reasoning. Advances in Accounting Behavioral Research, 16, 149 - 181.

Brooks, Leonard J. 2007. Business and Professional Ethics. ThompsonSouth Western.

Devos, K. 2012. The Impact of Tax Professionals Upon the Compliance Behavior of Australian Individual Taxpayers, Revenue Law Journal, 22 (1), 1-26.

Fallah, Syaikhul. 2006. "Pengaruh Budaya Etis Organisasi Dan Orientasi Etika Terhadap Sensitivitas Etika (Studi Empiris Tentang Pemeriksa Internal di Bawasda Pemda Papua)" (tesis). Semarang: Universitas Diponegoro.
Forsyth, D. R. 1980. A Taxonomy of Ethical Ideology. Journal of Personality andSocial Psychology.Vol. 39, pp. 175-184.

Gusnardi. 2003. Analisis Perbandingan Faktorfaktor yang Mempengaruhi Judgment Penetapan Risiko Audit oleh Auditor yang Berpengalaman dan Auditor yang Belum Berpengalaman. Tesis Tidak terpublikasi, Bandung: Universitas Padjadjaran

Gusti, M. dan Syahril, Ali. 2007. Hubungan Skeptisisme Profesional Auditor Dan Situasi Audit, Etika, Pengalaman Serta Keahlian Audit Dengan Ketepatan Pemberian Opini Auditor Oleh Akuntan Publik.Simposium Nasional Akuntansi XI. Pontianak 23 - 24 Juli 2008.

Higgins and Kelleher. 2005. Comparative Perspectives on the EthicalOrientations of Human Resources, Marketing and Finance Functional Managers. Journal of Business Ethics. Vol.56, pp. 275-288.

Januarti, Indira. 2011. Analisis pengaruh pengalaman auditor, komitmen profesional, orientasi etis, dan nilai etika terhadap persepsi dan pertimbangan etis (auditor badan pemeriksa keuangan Indonesia). Simposium Nasional Akuntansi XIV.Aceh 20 - 23 Juli 2011.

Jones, T. M. 1991. Ethical Decision Making by Individuals in Organizations : AnIssue Contingent Model. Academy of Management Review.Vol. 16, pp. 366-395.

Jeffrey, C. and Weatherholt, N. 1996.Ethical Development, ProfessionalCommitment, and Rule Observance Attitudes: A Study Case of CPAs and Corporate Accountans. Behavioral Research in Accounting. Vol.8, pp. 8-36.

Kohlberg, L. 1969. Stage and Sequance: The Cognitive Developmental Approachto Socialization in D.A Goslin. Chicago: Rand McNally.Handbook of Socialization Theory and Research.pp. 347-480.

Kwon, I. W. G., and Banks, D. W. 2004.Factors Related To The Organizational And Professional Commitment Of Internal Auditors.Managerial Auditing Journal. Vol.19, pp.606-622.

Larkin, J. M. 1990.Does Gender Affect Auditor KAPs' Performance?. The Woman CPA. Spring pp. 20-24.

Peraturan Menteri Keuangan Republik Indonesia Nomor 111/PMK.03/2014 Tentang Konsultan Pajak. 
Shaub, M. K., Don, W. Finn and Paul, Munter. 1993. The Effects of Auditor'sEthical Orientation on Commitment and Ethical Sensitivity. Behavioral Research in Accounting. Vol. 5, pp. 145-169.

Sugiyono. 2010. Metode Penelitian Bisnis Kuantitatif, Kualitatif dan $R \& D$. Bandung: PT. Alfabeta Cipta.

Trevino, Linda Klebe. 1986. Ethical Decision Making in Organization: A PersonSituation
Interactionist Model. Academy of Management Review Review. pp.601-617.

Uyar,M., and Ozer, G. 2011. The Ethical Orientation And Professional Commitment: An Empirical Examination On Turkish Accountants. Availablefrom: www.ssrn.com.

Kementrian Keuangan.www.kemenkeu.go. id/ Berita/menkeu-tax-ratio-indonesia-di-bawahstandar. diunduh 19 Januari 2017. 